\title{
Mechanism of the effect of saikosaponin on atherosclerosis in vitro is based on the MAPK signaling pathway
}

\author{
LIN YANG, JIANLIN LIU and GUANGYU QI
}

Department of Vascular Surgery, First Affiliated Hospital of Xi'an Jiaotong University, Xi'an, Shaanxi 710061, P.R. China

Received January 18, 2017; Accepted August 8, 2017

DOI: $10.3892 / \mathrm{mmr} .2017 .7691$

\begin{abstract}
The present study aimed to investigate the effects of saikosaponin on oxidized low-density lipoprotein (ox-LDL)induced human umbilical vein endothelial cell (HUVEC) injury and apoptosis, and examine the involvement of the mitogen-activated protein kinase (MAPK) signaling pathway. The viability and apoptosis of HUVECs were detected using an MTT assay and flow cytometry. ELISA analysis was applied to measure the levels of tumor necrosis factor (TNF)- $\alpha$ and interleukin (IL)- 6 cytokines. Nuclear factor (NF)- $\kappa$ B p65 nuclear translocation was observed using immunofluorescence staining. The levels of intercellular adhesion molecule 1 and vascular cell adhesion molecule-1 were detected using reverse transcription-polymerase chain reaction analysis. The phosphorylation of B-cell lymphoma 2 (Bcl-2), Bcl-2-associated X protein (Bax), caspase-3 p38, c-Jun N-terminal kinase (JNK) and extracellular signal-regulated kinase (ERK)1/2 were detected using western blot analysis. The results revealed that saikosaponin increased the viability of the HUVECs and decreased the early-stage apoptotic rate of the HUVECs induced by ox-LDL. The expression levels of inflammatory cytokines in the injured vascular endothelial cells were decreased, the expression levels of adhesion molecules were reduced, the activity of superoxide dismutase was increased, and malondialdehyde content was decreased. Therefore, the inflammatory response and oxidative stress were inhibited. Simultaneously, the levels of Bcl-2 increased, the levels of Bax and caspase-3 decreased, and the nuclear translocation of NF- $\mathrm{B}$ p 65 was significantly inhibited. The protein levels of phosphorylated $\mathrm{p} 38$ and $\mathrm{JNK}$ were reduced, whereas that of ERK1/2 remained unaffected. It was concluded that the MAPK signaling pathway mediated HUVEC injury induced by ox-LDL. However, saikosaponin inhibited the HUVEC injury induced by ox-LDL through inhibiting the ERK1/2 and
\end{abstract}

Correspondence to: $\mathrm{Dr}$ Lin Yang, Department of Vascular Surgery, First Affiliated Hospital of Xi'an Jiaotong University, 277 Yanta West Road, Xi'an, Shaanxi 710061, P.R. China

E-mail: yanglin2016804803@163.com

Key words: saikosaponin, inflammation, human umbilical vein endothelial cells, mitogen-activated protein kinase signaling pathway p38 MAPK signaling pathways, and possibly also through the JNK and p38 MAPK signaling pathway.

\section{Introduction}

Atherosclerosis (AS) is the pathological basis of cardiovascular and cerebrovascular disease, and is a common disease endangering health, which can affect the elastic artery and elastic muscle arterial intima, leading to luminal sclerosis and stenosis, and subsequent coronary heart disease, cerebral infarction and thromboembolic disease amongst other serious complications. Due to changes in lifestyle and dietary habits, the incidence of coronary heart disease and stroke have increased each year, and have become major causes of mortality (1)

Mitogen-activated protein kinases (MAPKs) are responsible for extracellular signal transduction into the cell to induce cellular biological responses. MAPKs are important in the regulation of the cardiovascular system and have become a major target of pharmacological investigations (2).

Saikosaponin has several effects, as an anti-endotoxin and corticosterone hormone, inhibiting the activities of $\mathrm{Na}^{+}$and $\mathrm{K}^{+}$-ATP enzymes, immune regulation, anti-platelet activity, anti-allergy effects, and anti-cell adhesion. However, few studies have examined its effects on the mechanism of AS, Therefore, examining the role of saikosaponin in treating AS is of important clinical significance.

\section{Materials and methods}

Cell resuscitation, culture and MTT assay detection of the inhibitory effect of saikosaponin on oxidized low density lipoprotein (ox-LDL)-induced HUVEC injury. The HUVECs (Type Culture Collection of the Chinese Academy of Sciences, Shanghai, China) were resuscitated and cultured in low-glucose Dulbecco's modified Eagle's medium (DMEM; Gibco; Thermo Fisher Scientific, Inc., Waltham, MA, USA) containing 10\% fetal bovine serum (Gibco; Thermo Fisher Scientific, Inc.), $100 \mathrm{U} / \mathrm{ml}$ penicillin, and $100 \mathrm{~g} / \mathrm{ml}$ streptomycin, in an incubator at $37^{\circ} \mathrm{C}$ and $5 \% \mathrm{CO}_{2}$. The cells in logarithmic growth phase were harvested and seeded into a 96-well plate at a density of $1 \times 10^{4}$ cells, with $100 \mu \mathrm{l} /$ well. The cells were incubated in a $5 \% \mathrm{CO}_{2}$ incubator. Following cell adherence, the medium was replaced with serum-free medium, and the cells were cultured for another $24 \mathrm{~h}$ to the stationary phase of synchronization, or the G0 phase. The cells were divided into five groups: Model 
group; control group; low dose group (10 $\mu \mathrm{M}$ saikosaponin); middle dose group (20 $\mu \mathrm{M}$ saikosaponin); and high dose group (40 $\mu \mathrm{M}$ saikosaponin). The cells in the model group and the control group were treated with an equal volume of serum-free DMEM low-glucose culture medium. After $30 \mathrm{~min}$, the cells in the model group and the saikosaponin treatment groups were exposed to ox-LDL at a density of $100 \mu \mathrm{g} / \mathrm{ml}$. An equal volume of serum-free DMEM low-glucose medium was added to the cells in control group, and all cells were cultured for another 24 or $48 \mathrm{~h}$. To each well, $20 \mu \mathrm{l}$ MTT solution $(5 \mathrm{mg} / \mathrm{ml})$ was added for $4 \mathrm{~h}$. Following this, the supernatant was discarded and replaced with $150 \mu \mathrm{l}$ DMSO. The medium was agitated for 10 min, until the dark blue crystals were sufficiently dissolved. The absorbance at a wavelength of $570 \mathrm{~nm}$ was measured with a microplate reader and the cell viability was calculated.

Flow cytometric analysis of the inhibitory effect of saikosaponin on the apoptosis of ox-LDL-induced HUVECs. Cells were initially treated in the same way as in the MTT assay being divided into 5 groups. The cells were collected and placed into a centrifuge tube at a density of $1 \times 10^{6}$ cells. Centrifugation was performed at $111.8 \mathrm{x} \mathrm{g}$ under $4^{\circ} \mathrm{C}$ for $5 \mathrm{~min}$ and the supernatant was discarded. A total of $200 \mu \mathrm{l}$ Binding Buffer was added to re-suspend the cells, and a mixture of $10 \mu \mathrm{l}$ Annexin V-FITC and $10 \mu \mathrm{l}$ PI staining solution was added and gently agitated. The cells were placed at room temperature in the dark for $15 \mathrm{~min}$, followed by the addition of $300 \mu \mathrm{l}$ Binding Buffer. The apoptosis of cells was detected within $1 \mathrm{~h}$ using flow cytometry.

ELISA to detect the effects of saikosaponin on the levels of tumor necrosis factor (TNF)- $\alpha$, interleukin (IL)-6, superoxide dismutase (SOD) and malondialdehyde (MDA) in HUVECs induced by $o x-L D L$. The cells were treated as described for the MTT assay. The supernatant was collected and cultured. The expression levels of TNF- $\alpha$, IL-6, SOD and MDA in the HUVECs were detected using a double antibody sandwich ELISA kit, in accordance with the manufacturer's protocol of the ELISA kit.

Immunofluorescence staining to detect the effects of saikosaponin on the nuclear transfer of nuclear factor $(N F)-\kappa B$ in HUVECs induced by ox-LDL. Sterilized coverslips were placed in a 6-well culture plate, onto which the well-grown HUVECs in the logarithmic phase were inoculated at a cell density of $1 \times 10^{4}$ per well, and the cells were treated according to the method used for the MTT assay. The climbing cell tablets were fixed in $4 \%$ paraformaldehyde solution for $30 \mathrm{~min}$, followed by washing with PBS three times, for $5 \mathrm{~min}$ each time. A total of $5 \mathrm{ml}$ non-immune goat serum (Gibco; Thermo Fisher Scientific, Inc.) was added in a drop-wise manner. The cells were incubated for $20 \mathrm{~min}$ at room temperature, following which excess solution was discarded and NF- $\kappa \mathrm{B}$ monoclonal antibody solution (1:200; cat. no. 554184; BD Biosciences, Franklin Lakes, NJ, USA) was added for overnight incubation at $4^{\circ} \mathrm{C}$. The coverslips were removed and washed three times with PBS, for 5 min each. Subsequently, goat anti-mouse immunoglobulin (Ig) G labeled with rhodamine (1:100; cat. no. SY0686; Biomics Laibo Technology Co., Ltd., Beijing, China) was added and incubated for $1 \mathrm{~h}$ at room temperature. The cells were then washed with PBS three times, for 5 min each, following which nuclei were stained with DAPI. Finally, the cells were sealed with $50 \%$ glycerol, and positive photographic microscopy was performed under a Nikon ECLIPSE 80i microscope (Nikon Corporation, Tokyo, Japan).

Reverse transcription-polymerase chain reaction (RT-PCR) assay to detect the effects of saikosaponin on adhesion molecule gene expression in ox-LDL-induced HUVECs. A total of $1 \mathrm{ml} \mathrm{TRIzol}{ }^{\circledR}$ reagent (Invitrogen; Thermo Fisher Scientific, Inc.) was added to the cells for sufficient lysis, followed by the addition of $0.2 \mathrm{ml}$ chloroform and agitation, and standing in an ice-bath for $5 \mathrm{~min}$. The cells were then centrifuged for $20 \mathrm{~min}$ at $4^{\circ} \mathrm{C}$ and $1,609.92 \mathrm{x} \mathrm{g}$. The supernatant was replaced with an equal volume of isopropanol, and placed in an ice-bath for $5 \mathrm{~min}$. The cells were centrifuged again for $20 \mathrm{~min}$ at $4^{\circ} \mathrm{C}$ and $1,609.92 \times \mathrm{g}$, following which the supernatant was discarded and $1 \mathrm{ml} \mathrm{75 \%}$ ethanol was added. The cells were centrifuged again for $20 \mathrm{~min}$ at $4^{\circ} \mathrm{C}$ and $1,609.92 \mathrm{x} \mathrm{g}$. The supernatant was carefully removed and the EP tube was inverted and dried for $15 \mathrm{~min}$ at room temperature. RNase-Free $\mathrm{ddH}_{2} \mathrm{O}(20 \mu \mathrm{l})$ was added to dissolve the precipitate following drying of the sediment. Subsequently, $1 \mu$ l solution was suctioned with an Eppendorf, and the remainder was stored in a deep freeze refrigerator at $-70^{\circ} \mathrm{C}$. The $1 \mu \mathrm{l}$ of solution was diluted into $80 \mu \mathrm{l}$ with diethyl pyrocarbonate $\mathrm{ddH}_{2} \mathrm{O}$. The ratio of OD260 to OD280 was measured using a spectrophotometer and the quantity of RNA was calculated. The synthesis of cDNA and RT procedures were performed according to manufacturer's protocol of the PrimeScript RT reagent kit with the following: 12.5 $\mu$ l SYBR Premix Ex Taq, $1 \mu$ l PCR forward primer, $1 \mu 1$

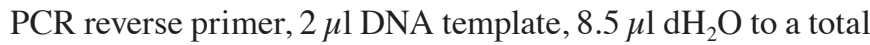
of $25 \mu \mathrm{l}$. The fluorescence RT-PCR was performed as follows: Amplification curve: Pre-denaturation for $5 \mathrm{~min}$ at $95^{\circ} \mathrm{C}$, denaturation for $20 \mathrm{sec}$ at $95^{\circ} \mathrm{C}$, annealing at $60^{\circ} \mathrm{C}$ for $30 \mathrm{sec}$, extension at $72^{\circ} \mathrm{C}$ for $20 \mathrm{sec}$. This stage was for fluorescence signal acquisition, comprising a total of 40 cycles; dissolution curve: $60-95^{\circ} \mathrm{C}$ in increments of $0.5^{\circ} \mathrm{C}$ per cycle, for $20 \mathrm{sec}$, this stage was for fluorescence signal acquisition, comprising a total of 71 cycles. The PCR product size was verified by $10 \mu \mathrm{l}$ electrophoresis on a $1 \%$ agarose gel. The primer sequences were as follows: Intercellular adhesion molecule 1 (ICAM-1) forward, 5'-CAATACGTCGCACCGCCTT-3' and reverse, 5'-ACTT GATACGGTGCTACTT-3'; vascular cell adhesion molecule 1 (VCAM-1) forward, 5'-CGCAGAAGTACATTCGG-3' and reverse, 5'-CCCACTGAGGCAAGTACACTG-3'; and GAPDH forward, 5'-ACCTCCTCGTTACGACAT-3' and reverse, 5'-GCACTTACTCACTGCCGTTG-3'.

Western blot analysis to detect the expression levels of caspase-3, B-cell lymphoma 2 (Bcl-2), Bcl-2-associated X protein (Bax), extracellular signal-regulated kinase (ERK)1/2, phosphorylated (p-)ERK1/2, P-38, p-p38, c-Jun N-terminal kinase (JNK) and $p-J N K$. The cells were collected and washed twice in PBS, and $400 \mu \mathrm{l}$ of lysate was added to each flask with $40 \mu \mathrm{l}$ PMSF (10 mmol/l). The flasks were gently shaken and then placed on ice $10 \mathrm{~min}$ for sufficient lysis. The cells were aspirated repeatedly with a sterile syringe. The lysate was transferred to an EP tube, and placed in an ice-bath for $30 \mathrm{~min}$, followed by centrifugation for $15 \mathrm{~min}$ at $12,000 \mathrm{x} \mathrm{g}$ at $4^{\circ} \mathrm{C}$. The supernatant was transferred to a new EP tube, and the protein density was determined using 
the ELISA method. To each tube, $20 \mu \mathrm{l} 6 \mathrm{X}$ buffer was added for every $100 \mu \mathrm{l}$, and was boiled for $5 \mathrm{~min}$. Following mixing, the samples were stored at $-80^{\circ} \mathrm{C}$. The proteins $(50 \mu \mathrm{g} /$ lane $)$ from the above samples were separated by electrophoresis on a $12 \%$ SDS-PAGE gel. The separated proteins were transferred onto a PVDF membrane through a wet method, and maintained at room temperature for $1 \mathrm{~h}$. Subsequently, primary antibodies against caspase-3 (cat. no. 9661; Cell Signaling Technology Inc., Danvers, MA, USA), anti-Bcl-2 (cat. no. sc-7382; Santa Cruz Biotechnology, Inc., Dallas, TX, USA) anti-Bax (cat. no. sc-6236; Santa Cruz Biotechnology, Inc.), anti-ERK1/2 (cat. no. LT9996; LifeTein,LLC., Somerset, NJ, USA), anti-p-ERK1/2 (cat. no. LT5646; LifeTein, LLC.), anti-P-38 (cat. no. sc-166182; Santa Cruz Biotechnology, Inc.), anti-p-p38, anti-JNK (cat. no. RB020016; RayBiotech, Inc, Norcross, GA, USA) and anti-p-JNK (cat. no. sc-6254; Santa Cruz Biotechnology, Inc.) were added to the membranes (all at 1:1,000) and the cells were incubated at $4{ }^{\circ} \mathrm{C}$ overnight. The cells were then washed with PBST three times and the secondary horse radish peroxidase conjugated antibody goat anti-mouse IgG (cat. no. A00160; 1:1,000; Kings Global Biotech, Ltd., Maharashtra, India) was added. The cells were incubated for $1 \mathrm{~h}$ at $4^{\circ} \mathrm{C}$, and then washed with PBST three times. Subsequent color development and fixation were performed following visualization with the enhanced chemiluminescence luminous liquid kit (cat. no. WBKLS0050; EMD Millipore, Billerica, MA, USA). The expression levels of the above proteins were measured and quantified using Image $\mathrm{J}$ analysis software (version 1.48U; National Institutes of Health, Bethesda, MD, USA).

Statistical analysis. All data are expressed as the mean \pm standard deviation. Comparisons between the two groups were performed using a unpaired Student's t-test, and multiple sets of data (>2) were compared using one-way analysis of variance. $\mathrm{P}<0.05$ was considered to indicate a statistically significant difference. All data were analyzed using GraphPad Prism 5.0 (GraphPad Software, Inc., La Jolla, CA, USA).

\section{Results}

Inhibitory effects of saikosaponin on ox- $L D L$-induced HUVEC injury. The results showed that ox-LDL at a concentration of $100 \mu \mathrm{g} / \mathrm{ml}$ caused significant cell damage, and decreased cell viability. Saikosaponin at all concentrations (10, 20 and $40 \mu \mathrm{M})$ inhibited the ox-LDL-induced HUVEC injury and improved cell viability, particularly at a concentration of $40 \mu \mathrm{M}$, as shown in Fig. 1.

Flow cytometry detection of the inhibitory effects of saikosaponin on ox-LDL-induced HUVEC apoptosis. The results demonstrated that, compared with the control group, the proportion of HUVECs in early stage apoptosis in the model group increased significantly. However, compared with the model group, the saikosaponin-treated groups showed significant decreases in early stage apoptosis of HUVECs, particularly at in the $40 \mu \mathrm{M}$ group, as shown in Fig. 2.

Effects of saikosaponin on expression levels of TNF- $\alpha, I L-6$, SOD and MDA in ox-LDL-induced HUVECs. The results showed that, compared with the control group, the levels

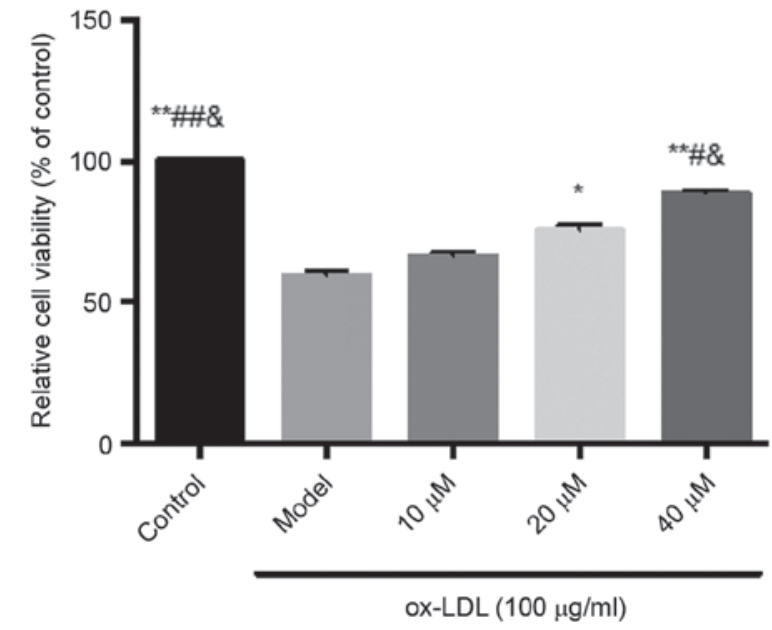

Figure 1. Inhibitory effects of saikosaponin on ox-LDL-induced human umbilical vein endothelial cell injury. ${ }^{* *} \mathrm{P}<0.01$ vs. Model; ${ }^{*} \mathrm{P}<0.05$ vs. Model; ${ }^{\# \prime} \mathrm{P}<0.01$ vs. $10 \mu \mathrm{M} ;{ }^{\#} \mathrm{P}<0.05$, vs. $10 \mu \mathrm{M}$; ${ }^{\&} \mathrm{P}<0.05$, vs. $20 \mu \mathrm{M}$. ox-LDL, oxidized low-density lipoprotein.

of TNF- $\alpha$, IL-6, SOD and MDA in the model group were significantly increased, and the level of SOD was significantly decreased. Compared with the model group, the levels of TNF- $\alpha$, IL- 6 and MDA in the saikosaponin-treated groups were decreased, and the level of SOD was increased, particularly in the $40 \mu \mathrm{M}$ group with statistical significance (Table I).

Effects of saikosaponin on the nuclear transfer of $N F-\kappa B$ p65 in ox-LDL-induced HUVECs. The results of the immunofluorescence analysis showed that NF- $\mathrm{KB}$ p65, visible in red, was expressed in the cytoplasm and nucleus. Following DAPI staining, the positively-stained nuclei were blue, which indicated the location of the nucleus. Compared with the control group, the level of NF- $\kappa$ B p65 was significantly increased in the nucleus of thr model group. However, compared with the model group, the level of NF- $\kappa \mathrm{B}$ p65 was significantly decreased in the nucleus of the saikosaponin-treated groups, particularly in the $40 \mu \mathrm{M}$ group, as shown in Fig. 3.

Effect of saikosaponin on the gene expression of adhesion molecules in ox-LDL-induced HUVECs. The results showed that, compared with the control group, the mRNA expression levels of ICAM-1 and VCAM-1 in the model group were increased. However, compared with the model group, the mRNA levels of ICAM-1 and VCAM-1 in the saikosaponin-treated groups were significantly decreased, particularly in the $40 \mu \mathrm{M}$ group, as shown in Fig. 4.

Effects of saikosaponin on the protein expression levels of caspase-3, Bcl-2, Bax, ERK1/2, p-ERK1/2, p38, p-p38, JNK and $p-J N K$. The protein expression levels of ERK1/2, p38 and JNK in the ox-LDL-induced HUVECs were similar among all groups; however, the expression levels of p-p38 and p-JNK were significantly different among groups (Fig. 5).

\section{Discussion}

The MAPK cascade is one of the most important signal transduction pathways in cells, and is involved in multiple biological 
Table I. Effects of saikosaponin on the levels of TNF- $\alpha$, IL-6, MDA and SOD in oxidized low-density lipoprotein-induced human umbilical vein endothelial cells.

\begin{tabular}{lcccc}
\hline Group & TNF- $\alpha(\mathrm{pg} / \mathrm{ml})$ & IL-6 $(\mathrm{pg} / \mathrm{ml})$ & MDA (nmol/mgprot) & SOD (nmol/mgprot) \\
\hline Control & $82.11 \pm 10.21^{\mathrm{a}, \mathrm{c}, \mathrm{f}}$ & $63.89 \pm 7.53^{\mathrm{a}, \mathrm{c}, \mathrm{e}}$ & $15.02 \pm 1.45^{\mathrm{a}, \mathrm{c}, \mathrm{f}}$ & $170.22 \pm 8.73^{\mathrm{a}, \mathrm{c}, \mathrm{f}}$ \\
Model & $125.28 \pm 12.90$ & $108.11 \pm 6.51$ & $32.99 \pm 2.73$ & $112.09 \pm 4.89$ \\
$10 \mu \mathrm{M}$ & $110.35 \pm 10.28^{\mathrm{b}}$ & $88.49 \pm 1.72$ & $29.02 \pm 2.09$ & $120.67 \pm 9.62$ \\
$20 \mu \mathrm{M}$ & $96.12 \pm 2.84^{\mathrm{b}}$ & $80.65 \pm 5.83^{\mathrm{b}}$ & $27.84 \pm 1.75$ & $133.89 \pm 4.91$ \\
$40 \mu \mathrm{M}$ & $90.23 \pm 2.21^{\mathrm{a}, \mathrm{d}}$ & $71.89 \pm 6.66^{\mathrm{a}, \mathrm{c}, \mathrm{f}}$ & $19.04 \pm 1.10^{\mathrm{a}, \mathrm{c}, \mathrm{f}}$ & $156.69 \pm 1.23^{\mathrm{a}, \mathrm{c}}$ \\
\hline
\end{tabular}

${ }^{\mathrm{a}} \mathrm{P}<0.01$, vs. Model; ${ }^{\mathrm{b}} \mathrm{P}<0.05$, vs. Model; ${ }^{\mathrm{C}} \mathrm{P}<0.01$. vs. $10 \mu \mathrm{M}$; ${ }^{\mathrm{d}} \mathrm{P}<0.05$, vs. $10 \mu \mathrm{M}$; ${ }^{\mathrm{e}} \mathrm{P}<0.01$, vs. $20 \mu \mathrm{M}$; ${ }^{\mathrm{P}} \mathrm{P}<0.05$, vs. $20 \mu \mathrm{M}$. TNF- $\alpha$, tumor necrosis factor-; IL-6, interleukin-6; MDA, malondialdehyde; SOD, superoxide dismutase.
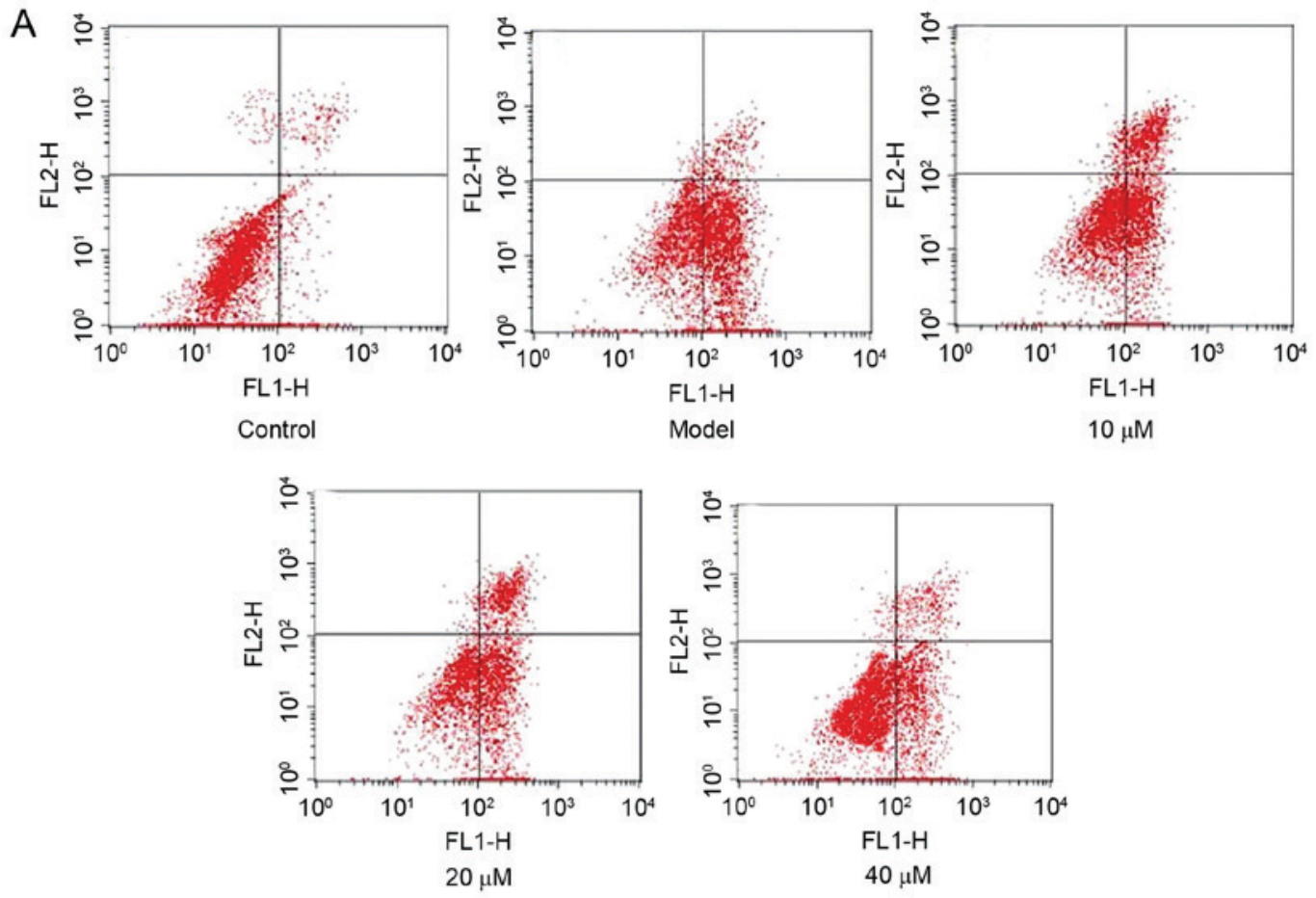

B

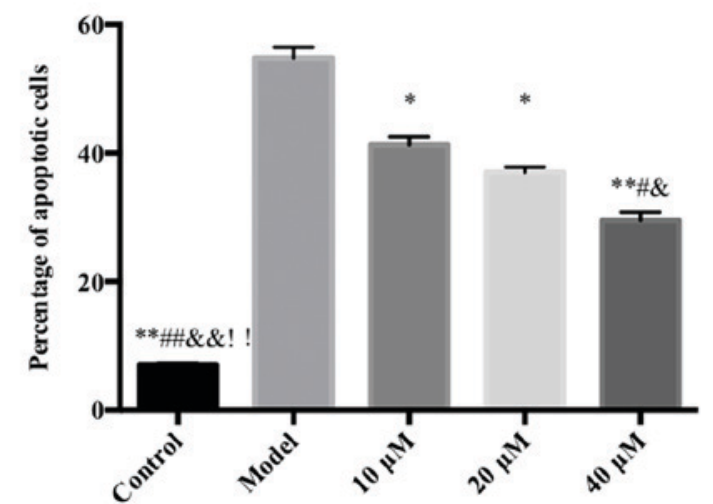

Figure 2. Flow cytometric analysis of the inhibitory effects of saikosaponin on oxidized low-density lipoprotein-induced human umbilical vein endothelial cell injury. (A) Flow cytometry data of control, model and 10, 20 and $40 \mu \mathrm{M}$ saikosaponin treated human umbilical vein endothelial cells. (B) Quantitative results of flow cytometry data. ox-LDL, oxidized low density lipoprotein. ${ }^{*} \mathrm{P}<0.05$ vs. model, ${ }^{* *} \mathrm{P}<0.01$ vs. model; ${ }^{\#} \mathrm{P}<0.05$ vs. $10 \mu \mathrm{M} ;{ }^{\# \#} \mathrm{P}<0.01 \mathrm{vs}$. $10 \mu \mathrm{M}$; ${ }^{\&} \mathrm{P}<0.05$ vs. $20 \mu \mathrm{M}$; ${ }^{\&} \mathrm{P}<0.01$ vs. $20 \mu \mathrm{M}$; "P<0.01 vs. $40 \mu \mathrm{M}$.

responses. There are three MAPK signaling pathways in mammalian cells, namely the ERK, JNK and p38 MAPK pathways (2). The MAPK signaling pathway is dormant when unstimulated, but is activated by the cascade phosphorylation of upstream kinases. The activated MAPKs enter the nucleus and facilitate the phosphorylation of transcription factors, 


\section{A}
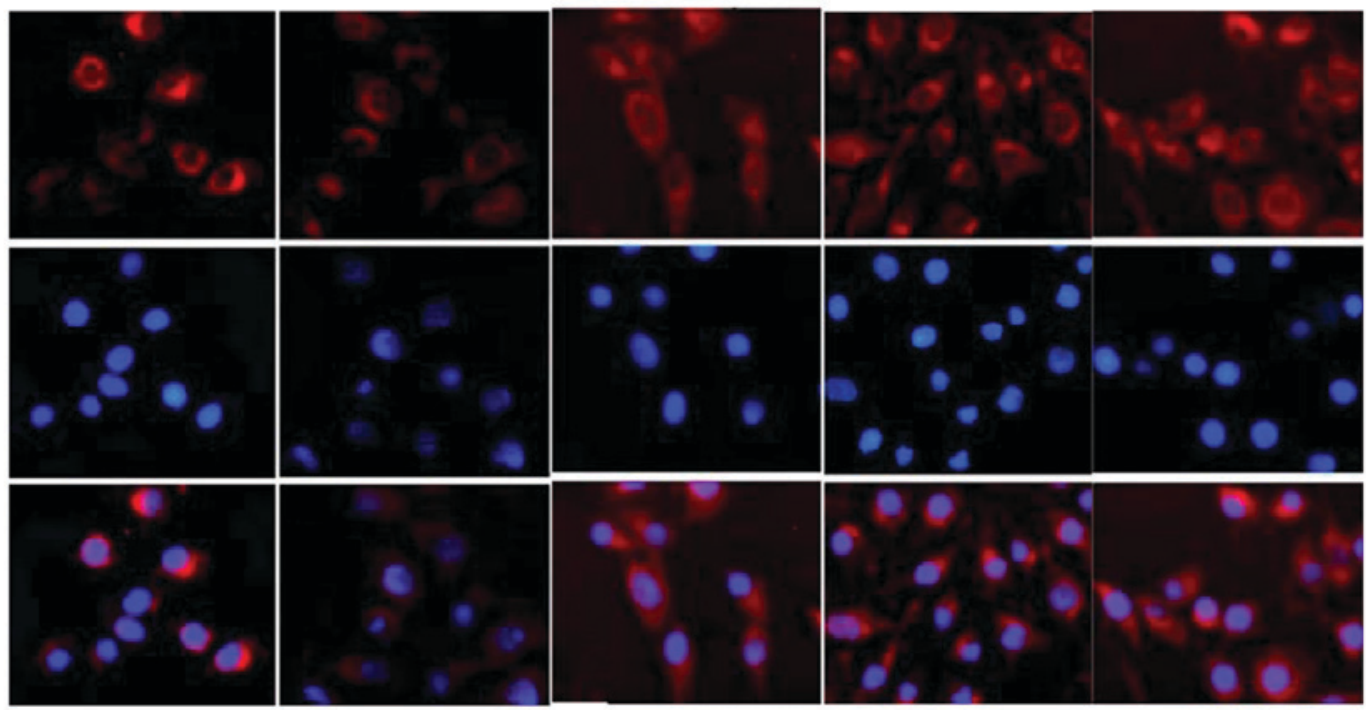

Control

Model

$10 \mu \mathrm{M}$

$20 \mu \mathrm{M}$

$40 \mu \mathrm{M}$

B
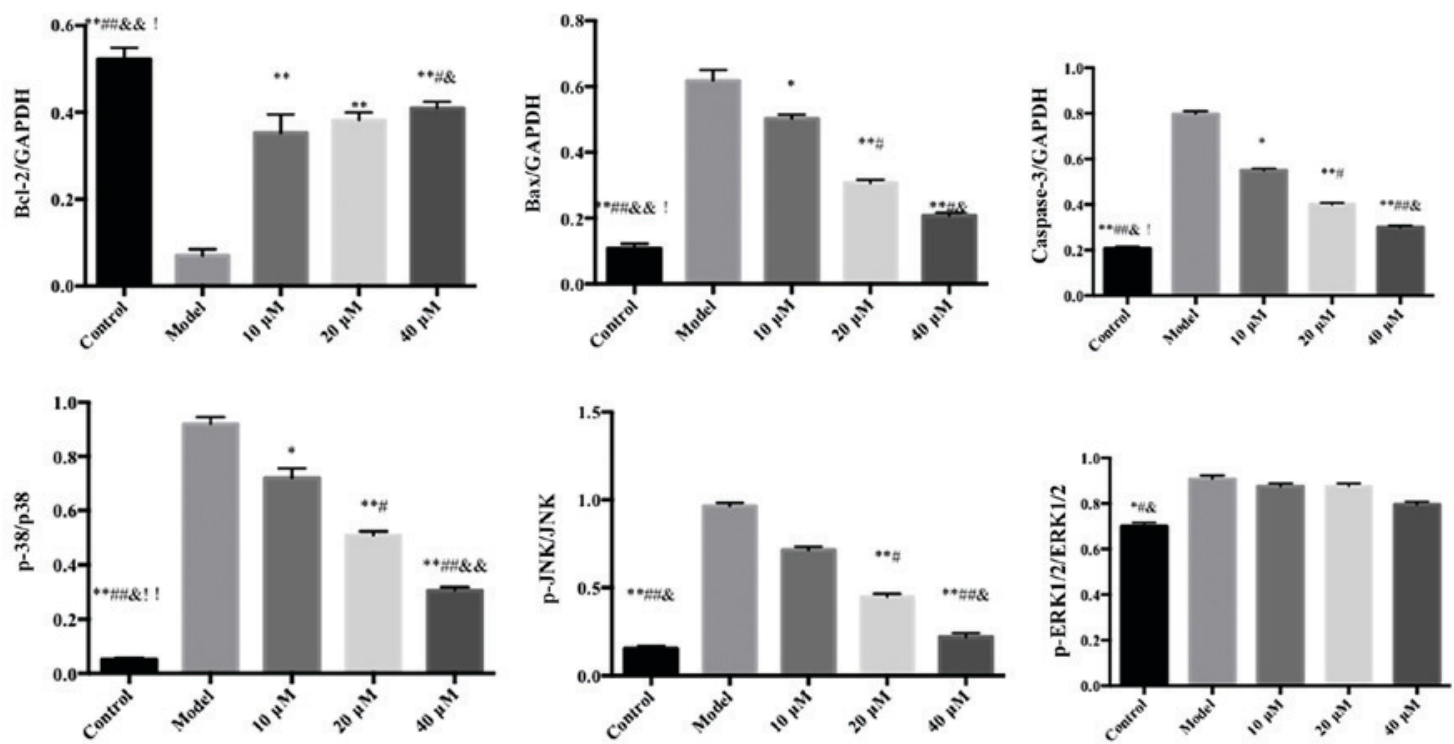

Figure 3. Effect of saikosaponin on nuclear factor- $\mathrm{B}$ p65 nuclear transfer. Magnification, x200. (A) Immunofluorescence data of control, model and 10, 20 and $40 \mu \mathrm{M}$ saikosaponin treated human umbilical vein endothelial cells. (B) Quantitative results of immunnofluorescence data. ${ }^{*} \mathrm{P}<0.05$ vs. model, ${ }^{* *} \mathrm{P}, 0.01$ vs. model; ${ }^{\#} \mathrm{P}<0.05$ vs. $10 \mu \mathrm{M} ;{ }^{\# \#} \mathrm{P}<0.01$ vs. $10 \mu \mathrm{M}$; ${ }^{\&} \mathrm{P}<0.05$ vs. $20 \mu \mathrm{M}$; \& ${ }^{\&} \mathrm{P}<0.01$ vs. $20 \mu \mathrm{M} ;{ }^{\prime} \mathrm{P}<0.05$ vs. $10 \mu \mathrm{M}$; !'P<0.01 vs. $40 \mu \mathrm{M}$.

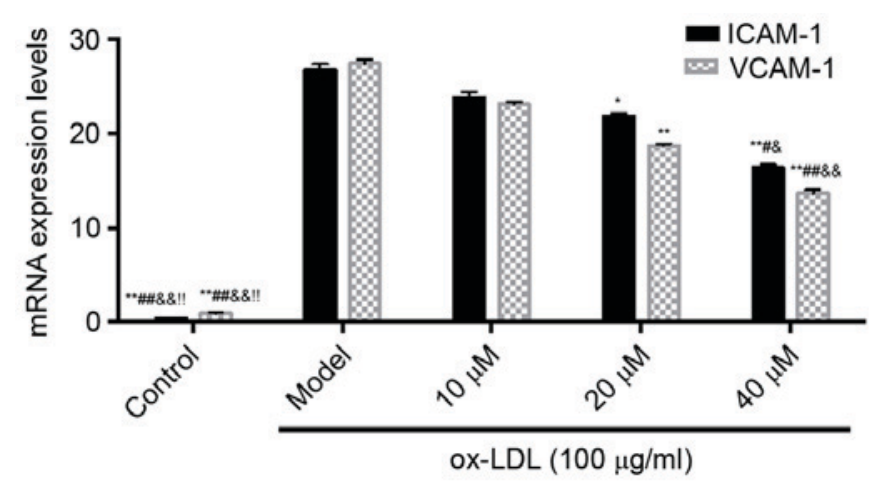

Figure 4. Effects of saikosaponin on the mRNA expression levels of ICAM-1 and VCAM-1. ${ }^{* *} \mathrm{P}<0.01$, vs. Model; ${ }^{*} \mathrm{P}<0.05$, vs. Model; ${ }^{\# \#} \mathrm{P}<0.01$ vs. $10 \mu \mathrm{M}$; ${ }^{\#} \mathrm{P}<0.05$, vs. $10 \mu \mathrm{M}$; ${ }^{\& \&} \mathrm{P}<0.01$ vs. $20 \mu \mathrm{M}$; ${ }^{\&} \mathrm{P}<0.05$ vs. $20 \mu \mathrm{M}$; ' $\mathrm{P}<0.05$ vs. $40 \mu \mathrm{M}$. ICAM-1, intercellular adhesion molecule 1; VCAM-1, vascular cell adhesion molecule-1; ox-LDL, oxidized low-density lipoprotein. which alter the gene expression of the cell, and are involved in the processes of cell proliferation, differentiation, transformation and apoptosis $(3,4)$.

In the p38 MAPK pathway, MAPK kinase (MKK) 4 can inhibit the MAPK signaling pathway, whereas MKK3/6 can phosphorylate and activate MKK, thus activating MAPK and further phosphorylating downstream molecules, including protein kinase, phospholipase and transcription factors. MAPK specifically regulates gene expression and is involved in the transduction processes of cell proliferation, differentiation and apoptosis (5-7).

In mammalian cells, the ERK pathway is considered to be the classic MAPK signaling pathway involved in cell proliferation and differentiation, mediated by growth cytokines, whose signal transduction requires the activation of ERK1/2 $(8,9)$.

JNK is a member of the MAPK superfamily. Being expressed in the cytoplasm, JNK can activate downstream 

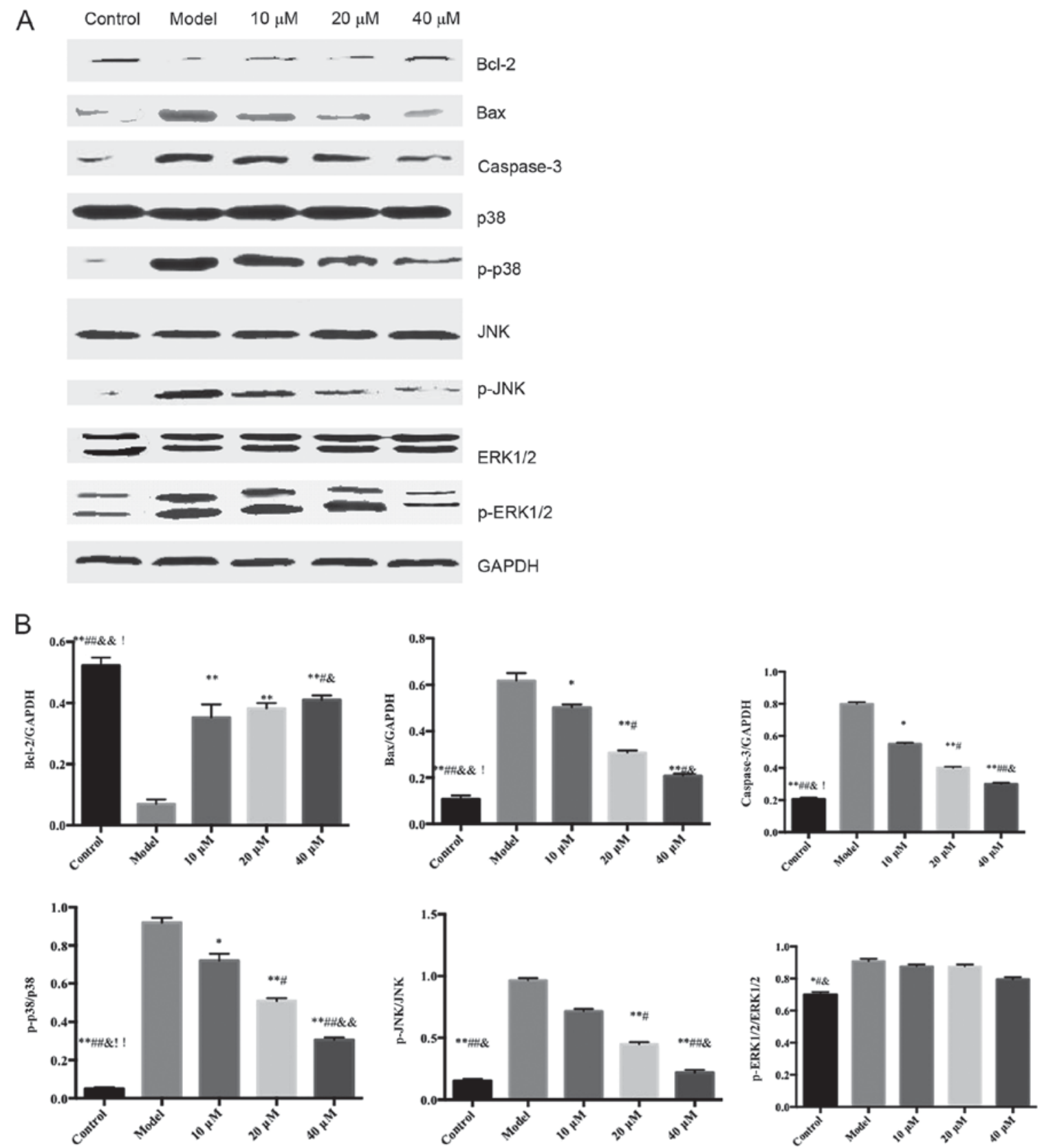

Figure 5. Effects of saikosaponin on the protein expression levels of caspase-3, Bcl-2, Bax, ERK1/2, p-ERK1/2, p38, p-p38, JNK and p-JNK. (A) Blots demonstrate the expression levels of proteins. (B) Quantitative results of the western blotting. ${ }^{*} \mathrm{P}<0.05$ vs. model, ${ }^{* * *} \mathrm{P}<0.01$ vs. model; ${ }^{\#} \mathrm{P}<0.05$ vs. $10 \mu \mathrm{M}$; ${ }^{\# \#} \mathrm{P}<0.01$ vs. $10 \mu \mathrm{M}$; ${ }^{\&} \mathrm{P}<0.05$ vs. $20 \mu \mathrm{M}$; \&\&P $<0.01$ vs. $20 \mu \mathrm{M}$; 'P $<0.05$ vs. $40 \mu \mathrm{M}$, ,"P $<0.01$ vs. $40 \mu \mathrm{M}$. Bcl-2, B-cell lymphoma 2; Bax, Bcl-2-associated X protein; ERK, extracellular signal-regulated kinase; p-, phosphorylated.

nuclear transcription factors through transcriptional- and non-transcriptional-dependent forms. The activation of JNK occurs through the phosphorylation of amino terminal residues. Following activation, JNK shifts to the nucleus (10-12). JNK is important in cell stress response and is involved in regulating apoptosis (13). Normally, the phosphorylation levels of MAPK determine the activity of JNK $(14,15)$.

The present study found that saikosaponin inhibited ox-LDL-induced HUVEC injury. The activity of SOD was increased, whereas MDA content was decreased. The levels of JNK and p38 phosphorylation were decreased; therefore, the oxidative stress injury in the HUVECs induced by ox-LDL was inhibited. In addition, saikosaponin prevented $\mathrm{NF}-\kappa \mathrm{B}$ from being induced into the nucleus, inhibited the secretion of inflammatory cytokines (TNF- $\alpha$ and IL-6) and adhesion molecules (ICAM-1 and VCAM-1), increased the expression of $\mathrm{Bcl}-2$, and decreased the expression of caspase- 3 and Bax, thereby inhibiting the apoptosis of ox-LDL-induced HUVECs. The different effects of saikosaponin on the phosphorylation of ERK1/2, JNK and p38 in the HUVECs suggested that HUVECs may be involved in the occurrence and development of AS through their unique respective signaling pathways.

In conclusion, saikosaponin significantly inhibited AS, which may have been through inhibiting the activation of $\mathrm{p} 38$ and ERK1/2 signaling pathways, thus having an anti-proliferative effect on smooth muscle cells. Through inhibiting the JNK and p38 signaling pathways, inhibiting the p38 and 
$\mathrm{NF}-\kappa \mathrm{B}$ protein cascade, saikosaponin inhibited injury and apoptosis of the endothelial cells.

\section{Acknowledgements}

This study was supported by the Foundation of Ministry of Science of Shaanxi Province, China (grant no. 2012K15-02-05).

\section{References}

1. Lee SM,Lee YJ,Kim YC, Kim JS, Kang DG and Lee HS: Vascular protective role of vitexicarpin isolated from Vitex rotundifolia in human umbilical vein endothelial cells. Inflammation 35 584-593, 2012.

2. Madonna R, Massaro M, Pandolfi A, Consoli A and De Caterina R: The prominent role of $\mathrm{p} 38$ mitogen-activated protein kinase in insulin-mediated enhancement of VCAM-1 expression in endothelial cells. Int J Immunopathol Pharmacol 20: 539-555, 2007.

3. Wang Z, Niu Q, Peng X, Li M, Liu Y, Liu J, Wen S and Wei Y: Mitofusin 2 ameliorates aortic remodeling by suppressing ras/raf/ERK pathway and regulating mitochondrial function in vascular smooth muscle cells. Int J Cardiol 178: 165-167, 2015.

4. Park B, Yim JH, Lee HK, Kim BO and Pyo S: Ramalin inhibits VCAM-1 expression and adhesion of monocyte to vascular smooth muscle cells through MAPK and PADI4-dependent NF- $\kappa B$ and AP-1 pathways. Biosci Biotechnol Biochem 79: 539-552, 2015.

5. Martin-Blanco E: p38 MAPK signalling cascades: Ancient roles and new functions. Bioessays 22: 637-645, 2000

6. Chahine MN, Blackwood DP, Dibrov E, Richard MN and Pierce GN: Oxidized LDL affects smooth muscle cell growth through MAPK-mediated actions on nuclear protein import. J Mol Cell Cardiol 46: 431-441, 2009.
7. Wang GF, Shi CG, Sun MZ, Wang L, Wu SX, Wang HF, Xu ZQ and Chen DM: Tetramethylpyrazine attenuates atherosclerosis development and protects endothelial cells from ox-LDL. Cardiovase Drugs Ther 27: 199-210, 2013.

8. Fisk M, Gajendragadkar PR, Mäki-Petäjä KM, Wilkinson IB and Cheriyan J: Therapeutic potential of p38 MAP kinase inhibition in the management of cardiovascular disease. Am J Cardiovasc Drugs 14: 155-165, 2014.

9. Sun Y, Liu WZ, Liu T, Feng X, Yang N and Zhou HF: Signaling pathway of MAPK/ERK in cell proliferation, differentiation, migration, senescence and apoptosis. J Recept Signal Transduct Res 35: 600-604, 2015.

10. Glaros EN, Kim WS and Garner B: Myriocin-mediated up-regulation of hepatocyte apoA-I synthesis is associated with ERK inhibition. Clin Sci (Lond) 118: 727-736, 2010.

11. Dhanasekaran DN and Reddy EP: JNK signaling in apoptosis Oncogene 27: 6245-6251, 2008.

12. Yarza R, Vela S, Solas M and Ramirez MJ: c-Jun N-terminal Kinase (JNK) signaling as a therapeutic target for Alzheimer's disease. Front Pharmacol 6: 321, 2016.

13. Wei L, Deng W, Cheng Z, Guo H, Wang S, Zhang X, He Y and Tang Q: Effects of hesperetin on platelet-derived growth factor-BB-induced pulmonary artery smooth muscle cell proliferation. Mol Med Rep 13: 955-960, 2016.

14. Cui Y, Sun YW, Lin HS, Su WM, Fang Y, Zhao Y, Wei XQ Qin YH, Kohama K and Gao Y: Platelet-derived growth factor-BB induces matrix metalloproteinase-2 expression and rat vascular smooth muscle cell migration via ROCK and ERK/p38 MAPK pathways. Mol Cell Biochem 393: 255-263, 2014.

15. Kim MH, Kang HM, Kim CE, Han S and Kim SW: Ramipril inhibits high glucose-stimulated up-regulation of adhesion molecules via the ERK1/2 MAPK signaling pathway in human umbilical vein endothelial cells. Cell Mol Biol Lett 20: 937-947, 2015. 